ANUARIO DE ESTUdios MEDIEVALES

49/2, julio-diciembre de 2019, pp. 761-791

ISSN 0066-5061

https://doi.org/10.3989/aem.2019.49.2.14

\title{
LA ORIENTACIÓN DE LAS IGLESIAS ROMÁNICAS EN LA PENÍNSULA IBÉRICA*
}

\section{THE ORIENTATION OF ROMANESQUE CHURCHES IN THE IBERIAN PENINSULA}

\author{
JUAN PÉREZ VALCÁRCEL \\ Universidad de A Coruña. \\ https://orcid.org/0000-0002-6440-5432 \\ VICTORIA PÉREZ PALMERO \\ Universidad de A Coruña. \\ https://orcid.org/0000-0002-3364-5580
}

\begin{abstract}
Resumen: Las iglesias prerrománicas en Hispania (España y Portugal) están orientadas hacia el este, pero se observa un cierto número de desviaciones importantes. Por el contrario, la casi totalidad de las iglesias románicas en Hispania están orientadas hacia el este con desviaciones que sólo se apartan de posibles posiciones del orto solar en pocos casos. Únicamente en la Baja Edad Media aparecen iglesias góticas con orientaciones claramente diferentes. Sin embargo, la mayoría no están orientadas al este geográfico preciso, sino que pueden presentar variaciones de más de $30^{\circ}$ hacia el norte y hacia el sur. Es justamente lo que varía la posición del orto solar a lo largo del año y esto nos permite calcular con precisión de unos pocos días, el día concreto en que fueron orientadas. En este artículo trataremos de definir cuáles fueron los criterios utilizados y si ese día tiene un significado simbólico, litúrgico o funcional. También se analizará el sistema de medición necesario para una determinación precisa de dicho día y los factores que deben ser tenidos en cuenta en dicho cálculo, para conseguir la precisión adecuada, así como las conclusiones del estudio.
\end{abstract}

Palabras clave: iglesias románicas; orientación de las iglesias; orto solar; medida de la orientación; orientaciones simbólicas; orientaciones funcionales.

Abstract: Pre-Romanesque churches in Hispania (Spain and Portugal) generally face east, but very significant deviations can sometimes be observed. In contrast, almost all Romanesque churches in Hispania are oriented towards the east with deviations that vary from possible positions of the sunrise in only a very few cases. Only in the Late Middle Ages do Gothic churches appear with clearly different orientations. However, most are not oriented towards precise geographical east, but can display variations of more than 30 degrees north and south. This is precisely the variation in the position of sunrise in the course of the year, and it allows us to calculate the particular day when they were laid out within a few days. This article will attempt to define what the criteria used were and if that day had any symbolic, liturgical or functional significance. The measurement system required for an accurate determination of the day and the factors to be taken into account in the calculation to achieve the appropriate precision are also analysed. The conclusions of the study are also included.

Keywords: Romanesque churches; church orientation; sunrise; orientation measurement; symbolic orientations; functional orientations.

\footnotetext{
* Este estudio se ha realizado sin ningún tipo de ayuda oficial, pero los autores desean mostrar su agradecimiento a las muchas personas que con gran amabilidad les facilitaron el acceso a las iglesias estudiadas. Igualmente quieren mostrar su agradecimiento al profesor Ángel Rodríguez Arós de la E.T.S. de Náutica de A Coruña por su ayuda en los cálculos de la corrección del orto por la pendiente del horizonte.
}

Citation / Cómo citar este artículo: Pérez Valcárcel, Juan; Pérez Palmero, Victoria (2019), La orientación de las iglesias románicas en la Península Ibérica, "Anuario de Estudios Medievales” 49/2, pp. 761-791. https://doi.org/10.3989/ aem.2019.49.2.14

Copyright: (C) 2019 CSIC. Este es un artículo de acceso abierto distribuido bajo los términos de la licencia de uso y distribución Creative Commons Reconocimiento 4.0 Internacional (CC BY 4.0). 


\section{SUMARIO}

1. Introducción.- 2. La orientación de los templos cristianos.- 3. La orientación solar.- 4. Criterios de orientación de los templos románicos.- 5. Toma de datos de la orientación.- 6. Factores que intervienen en el cálculo de la orientación.- 7. Análisis de los criterios de orientación en los templos románicos en Hispania.- 8. Orientaciones atípicas.- 9. Conclusiones.- 10. Bibliografía citada.

\section{INTRODUCCIÓN}

La orientación de los templos cristianos hacia oriente es conocida desde antiguo. Sin embargo esta orientación no es precisa, sino que varía de forma sustancial con una amplitud de más de $60^{\circ}$, pero casi siempre dentro de posiciones que corresponden al orto solar. Con los cálculos astronómicos adecuados es posible determinar el día del año en el que una iglesia concreta fue replanteada. Es un problema de gran interés del que hay algunos notables estudios referidos a otros países, pero que prácticamente no ha sido analizado en el caso de la Península Ibérica.

Dejando aparte algunos trabajos anteriores de poco rigor científico, este problema fue inicialmente estudiado por Heinrich Nissen ${ }^{1}$, dentro de un contexto general más centrado en el estudio de los templos griegos y romanos. Incluye también un importante apartado dedicado al cristianismo, pero sus resultados presentan algunos errores que hemos podido constatar. Por otra parte sus conclusiones no son válidas en el contexto hispánico, que no analiza. Ha habido algunas otras contribuciones posteriores, que se citarán, pero en el momento actual, con un mayor número de casos y un área estudiada más extensa, es posible abordar un estudio preciso en la Hispania románica que hasta el momento no había sido realizado.

En la figura 1 se pueden observar las trayectorias del sol a lo largo del año. La trayectoria aparente del sol es elíptica, pero se puede aproximar con un error muy reducido por una trayectoria circular inclinada desde la vertical un ángulo igual a la latitud del lugar de observación. En el equinoccio de primavera el sol sale exactamente por el este y se pone exactamente por el oeste. Pero el resto del año puede salir por cualquier punto comprendido entre el punto A (solsticio de invierno) y el punto B (solsticio de verano). Todo punto comprendido entre ambos corresponde al orto solar de dos días del año. Por tanto si conocemos la orientación de un templo que señala el punto $\mathrm{C}$ podemos calcular con gran precisión el día que fue orientado, aunque

${ }^{1}$ Nissen 1896, 1906. 
siempre hay dos días posibles, por ejemplo 6 de abril y 22 de agosto. El problema consistirá en determinar si el día elegido tiene algún significado y cuál de las dos fechas es la más probable.

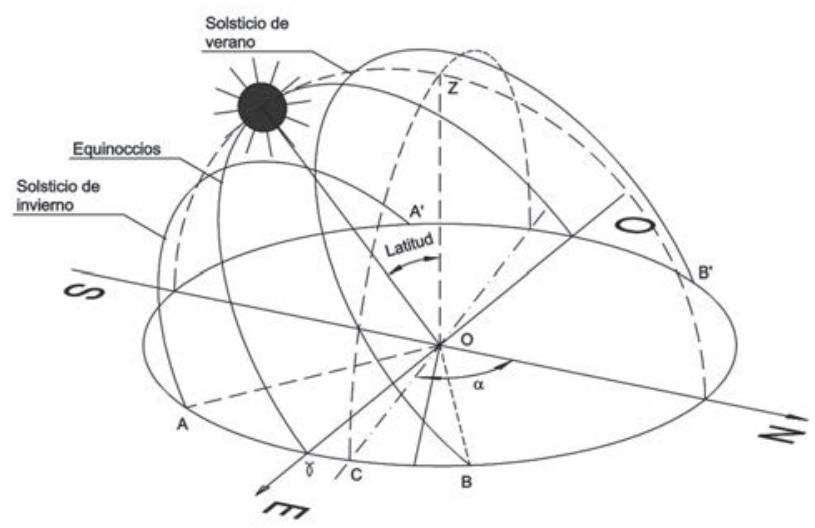

Fig. 1. Trayectorias anuales aparentes del sol.

En este trabajo se pretende dar una respuesta a la incógnita de por qué se eligió el día concreto en el que se orientaron las iglesias. El estudio se limita en el tiempo a la época del románico y en el espacio a la antigua Hispania, es decir España y Portugal. Más concretamente, el ámbito geográfico es el de los reinos de Asturias, León, Galicia, Portugal, Castilla, Navarra y Aragón, junto con los condados catalanes. Se han excluido los ámbitos geográficos que corresponden a Extremadura y Castilla la Nueva al sur del Tajo, el sur de Aragón, Valencia, Murcia y Andalucía, en los que el románico existente es escaso, tardío y desde nuestro punto de vista poco representativo.

Para el estudio que se propone se van a estudiar tres aspectos básicos. Corresponden a los estudios sobre la orientación solar de los templos cristianos y específicamente los templos románicos en la Península Ibérica, a la relación con los calendarios litúrgicos y los santorales que permiten la fijación de las fiestas eclesiásticas en el periodo y zona geográfica estudiados y por último a los propios datos que podemos deducir de los edificios. Para el estudio de las orientaciones en relación con el día del replanteo es necesario conocer la orientación precisa del templo, la altura del horizonte y la latitud del lugar. Estos son los datos básicos que nos van a proporcionar los edificios estudiados y con los que vamos a analizar las distintas posibilidades de orientación. 


\section{LA ORIENTACIÓN DE LOS TEMPLOS CRISTIANOS}

La orientación del espacio sagrado es una preocupación no sólo cristiana sino que viene de muy antiguo. Todos los lugares sagrados han tenido siempre una orientación generalmente definida por el sol, aunque algunos casos se han tomado como referencia las estrellas fijas. Por el contrario no se han considerado nunca posibles orientaciones lunares, puesto que la trayectoria de la luna recorre todo el horizonte ni tampoco trayectorias ligadas a los planetas, cuyo movimiento retrógrado siempre se consideró de mal augurio.

En el caso de los templos egipcios hay interesantes estudios como los de Lull en el que menciona junto con las bien conocidas orientaciones a determinadas estrellas, algunas notables orientaciones solares como las del templo de Horus edificado por Mentuhotep III, faraón de la XI Dinastía en Tebas o el gran templo de Karnak (XVIII Dinastía), igualmente en Tebas². En ambos casos la orientación coincide con una gran precisión con el orto solar en el solsticio de invierno.

La orientación de los templos cristianos es muy variable y no está ligada ni a los equinoccios ni a los solsticios. Algunos autores sostienen que la orientación de los templos coincide con la fiesta del santo titular, lo que denominaremos orientación simbólica. Es una afirmación discutible. A título de ejemplo las tres iglesias de Cluny, construidas en distintas épocas y ampliamente estudiadas, tienen orientaciones diferentes y no hay ningún dato de que se hubiera cambiado su advocación. También la iglesia de la Madeleine de Vézelay cuya advocación no es dudosa, tiene una orientación aproximadamente de $82^{\circ}$ que corresponde a una fecha de replanteo que corresponde al 27 de marzo o al 2 de septiembre cuando la fiesta se celebra el 22 de julio ${ }^{3}$. Son algunos ejemplos que nos hacen dudar de esta afirmación, si bien no hemos estudiado sistemáticamente las orientaciones en Francia, cuya importancia en la generación y desarrollo del románico es bien conocida. En el entorno anglosajón también las opiniones de los distintos investigadores parecen discrepar de esta aseveración. Por ello parece oportuno realizar este estudio en el entorno hispánico para comprobar si esta hipótesis se corresponde o no con los datos medidos por los autores.

Son relativamente pocos los estudios realizados sobre orientaciones de iglesias. De hecho uno de los investigadores más importantes, Hoare, afirma en uno de sus trabajos recientes: even after 330 years of investigation,

\footnotetext{
${ }^{2}$ Lull 2006, pp. 324-328.

${ }^{3}$ Esta fecha coincide en todos los santorales consultados.
} 
medieval church orientation studies in England are arguably still in their infancy ${ }^{4}$.

Es una afirmación exagerada, puesto que los primeros estudios realizados en Inglaterra se basan en suposiciones o tradiciones de origen masónico, más que discutibles, según citan Ali y $\mathrm{Cunich}^{5}$. El primer trabajo realizado con los criterios actuales en el entorno anglosajón es el de Cave en 1950, que en una de sus conclusiones afirma: there is no connexion whatsoever between the orientation of a church and the bearing of sunrise on the feast day of the saint whom the church is dedicated.

Los citados autores, Ali y Cunich, consideran que el trabajo de Cave presenta importantes lagunas y de hecho sus conclusiones indican que hay un porcentaje significativo de iglesias de un total de 141 que pueden considerarse orientadas en la fiesta del santo patrón (23\% al orto y $20 \%$ al ocaso). En sentido contrario Hinton señala que en un estudio de 550 iglesias en Norfolk no ha encontrado ninguna correlación sólida ${ }^{6}$.

Otra línea de investigación es la que han seguido investigadores nórdicos sobre el posible uso de brújulas para fijar la orientación de las iglesias. Se basan de los datos de la declinación magnética que en esa época suponía un valor importante, entre $10^{\circ}$ y $30^{\circ}$, lo que hacía que el este magnético estuviera entre $100^{\circ}$ y $120^{\circ}$. Son valores bastante anómalos y que al parecer se producen con cierta frecuencia en sus países. La hipótesis fue establecida por Abraham$\operatorname{sen}^{7}$ en 1992 y ha sido fuertemente contestada por los investigadores ingleses, puesto que estas variaciones no se producen en el entorno inglés. Pese a lo improbable de esta hipótesis, también se estudiará en el caso hispánico.

Es destacable el trabajo de Hoare y Sweet $^{8}$ sobre la orientación de las iglesias prerrománicas de Inglaterra, así como el referido a las iglesias parroquiales románicas, también en el entorno inglés, en el que proporciona un dato interesante y es que el $89 \%$ de iglesias inglesas medidas están orientadas entre $71^{\circ}$ y $109^{\circ}$, es decir que predomina la orientación equinoccial ${ }^{9}$. Además de las hipótesis de orientación habituales, añade una, la posible orientación correspondiente al 1 de mayo. Ese día tiene un importante significado en el entorno germánico y nórdico y al parecer algo menor pero también relevante en el entorno anglosajón. Corresponde al amanecer tras la noche de Walpurgis de gran tradición pagana. Es una hipótesis que han sustentado algunos autores

\footnotetext{
${ }^{4}$ Hoare 2015.

${ }^{5}$ Ali, Cunich 2001, pp. 155-156 .

${ }^{6}$ Hinton 2006, p. 222.

${ }^{7}$ Abrahamsen 1973, 1992.

${ }^{8}$ Hoare, Sweet 2000.

${ }^{9}$ Hoare 2015, p. 1714.
} 
que se citan en dicho artículo, pero los propios autores la descartan al no ser congruente con las orientaciones que han medido. Si esta hipótesis no es válida en el entorno anglosajón, podemos entender que en menor medida lo será en un entorno hispánico en el que esa tradición prácticamente no existe.

Un estudio completo y sistemático es el de Hinton que ha realizado un completo análisis de las orientaciones de las iglesias medievales de Inglaterra, incluyendo el efecto de la pendiente del horizonte. Ha realizado diversas publicaciones de sus resultados, que han culminado en su tesis doctoral de 2010. En general sus resultados son muy correctos, si bien los cálculos astronómicos que aporta se basan en considerar la trayectoria del sol como circular, lo que supone un cierto error, aunque no inhabilita en modo alguno sus conclusiones ${ }^{10}$.

Hay pocos estudios respecto a otros entornos geográficos. Rimvydas Laužikas analiza la orientación de diversos templos, tanto católicos como ortodoxos en el este de Europa, pero sin llegar a conclusiones claras ${ }^{11}$.

No hemos podido encontrar apenas estudios en el entorno hispánico. Sólo podemos citar el trabajo de Pérez Valcárcel ${ }^{12}$ sobre la orientación de 187 iglesias románicas españolas situadas en el camino de Santiago. En este estudio se analizaban las orientaciones en términos estadísticos, pero en este caso los datos no había sido corregidos con la consideración de la variación de la posición del orto solar cuando el horizonte esta en pendiente. Por el contrario si se había tenido en cuenta el efecto de la trayectoria solar elíptica con un método más preciso.

\section{LA ORIENTACIÓN SOLAR}

El primer aspecto que se debe abordar en este estudio son las posibles razones de la orientación solar dentro del contexto cristiano y en especial de los templos románicos en el entorno estudiado. Hay varios estudios sobre el tema, tanto el de Nissen ${ }^{13}$ como otros posteriores basados en datos más recientes y precisos $^{14}$.

Los templos cristianos empezaron en una situación de clandestinidad y muchas veces reaprovechando otros edificios destinados a usos diversos y esta situación duró bastante tiempo. Por ello no podemos hacer un análisis

\footnotetext{
${ }^{10}$ Hinton 2010, p. 330.

${ }^{11}$ Laužikas 2015.

${ }^{12}$ Pérez Valcárcel 1998.

${ }^{13}$ Nissen 1906.

${ }^{14}$ McCluskey 2015.
} 
fiable de sus orientaciones hasta mediados del siglo IV. De hecho es discutible su propia existencia como señala Krautheimer: en efecto, antes de 350 no existía la basílica cristiana como tal; había únicamente un gran número de variaciones sobre el tema de la basílica, adaptadas a los requisitos litúrgicos, la práctica constructiva y los deseos de quienes las costeaban ${ }^{15}$.

La situación cambia radialmente a partir del Edicto de Milán (313 d.C.) que permite el culto cristiano. Rápidamente se edifica un conjunto de grandes basílicas, que serán las primeras con una orientación definida y suscitan la duda si esa orientación se realizó por criterios solares o por criterios simbólicos, en especial en el caso de la más importante de ellas, la basílica del Santo Sepulcro de Jerusalén, edificada por orden directa de Constantino.

Según los estudios arqueológicos de Virgilio Corbo $^{16}$ la basílica estaba orientada simbólicamente hacia la Anástasis, construida exactamente sobre el Santo Sepulcro. Sin embargo se decidió mantener el peristilo de un templo de Venus, que daba al cardo maximo y que estaba aproximadamente situado en dirección norte-sur con una desviación según los datos de Corbo de $9^{\circ}$ al oeste, muy comprensible si tenemos en cuenta los fuertes desniveles de la ciudad $^{17}$. Para conseguir que la basílica se orientara a la Anástasis manteniendo el peristilo, el eje de la basílica está girado un ángulo de $6^{\circ}$ de tal forma que su orientación es aproximadamente $255^{\circ}$. Esta desviación supone un ángulo pequeño, pero era claramente perceptible porque el atrio resultaba bastante irregular. Todos estos datos apuntan a una orientación simbólica hacia el lugar más sagrado de la cristiandad y no específicamente a una orientación solar, aunque sería congruente.

Esta consideración simbólica es tan importante en este caso, que supera a cualquier otra, pero en otros lugares se puede plantear la duda de si las iglesias se orientan hacia Jerusalén o hacia un punto definido por el sol, este u oeste. Un caso que puede clarificar el tema es el de las iglesias sirias y en especial la más importante de ellas, la de S. Simeón Estilita, cerca de Alepo. Su orientación es claramente este (unos $103^{\circ}$ ). Si se hubiera intentado orientarla a Jerusalén estaría dirigida al sur, como por otra parte sucede en las mezquitas omeyas de Siria, en las que se busca la dirección de La Meca. La orientación a levante es la común en las iglesias cristianas y desde luego en las hispánicas

\footnotetext{
${ }^{15}$ Krautheimer 1984, p. 48.

${ }^{16}$ Corbo 1981

${ }^{17}$ Ignoramos si V. Corbo tuvo en cuenta la declinación magnética en sus mediciones, puesto que en numerosas ocasiones hemos comprobado que se algunos autores dan la medida directa de la brújula. Si no se consideró, la declinación magnética, los ángulos que se citan deben aumentarse en $2,5^{\circ}$, que es la declinación magnética aproximada en Jerusalén en las fechas del estudio de Corbo.
} 
y se hace en la dirección de la salida del sol en un día concreto del año, cuyo significado se desconoce ${ }^{18}$.

Como excepción las primeras basílicas constantinianas que orientan a poniente, por razones litúrgicas ${ }^{19}$. El sacerdote se colocaba mirando a los fieles, como se hace en la actualidad: esto fijaba la dirección al sol naciente para el sacerdote y la oeste para la comunidad cristiana. Esta orientación se utilizó sólo unos pocos años. De hecho la basílica de la Natividad en Belén, construida poco antes del año 333 d.C. ya está orientada a levante y esta será la regla tanto en las iglesias orientales como en las occidentales a partir del concilio de Nicea (325 d.C.). Sin embargo existen diversas basílicas, sobre todo las construidas en Roma que mantienen su orientación a poniente, pese a haber sido construidas posteriormente. Podemos citar entre otras, Sta. María la Mayor, S. Pedro del Vaticano, S. Lorenzo Extramuros y Sta. María de Trastevere. La basílica antigua de S. Pablo Extramuros y S. Juan de Letrán están igualmente orientadas al oeste, pero parecen haber sido consagradas en 324 d.C., es decir antes del citado concilio.

Una de las primeras referencias sobre la orientación aparece en $E l$ Apologético de Tertuliano 16.9-10 escrito en 197 d.C.

Otros...creen que el sol es nuestro dios... El origen de tal sospecha proviene del hecho notorio de que nosotros oramos vueltos hacia la región de oriente. Pero también muchos de vosotros, mostrando alguna vez veneración hacia los astros, movéis los labios vueltos hacia la salida del sol.

Un texto más explícito, aunque la Iglesia no lo considera canónico son las Constituciones Apostólicas redactadas alrededor del año $400^{20}$. En ellas se estipula que la casa de la comunidad debe ser de forma alargada, semejante a un barco y orientada hacia el este. Algunos textos litúrgicos posteriores añaden que la referencia a tomar es el punto preciso en el que sale el sol en el equinoccio de primavera ${ }^{21}$, lo que es perfectamente correcto desde

\footnotetext{
${ }^{18}$ En el apartado 1 del capítulo IX del libro de Nissen se estudia pormenorizadamente la simbología de la adoración del sol en diversas culturas y su relación con el cristianismo primitivo.

${ }^{19}$ Las basílicas construidas por Constantino con orientación oeste son las de S. Juan de Letrán, S. Pedro del Vaticano, S. Pablo Extramuros (la original) y la de S. Lorenzo Extramuros en Roma. En Oriente la Basílica de la Resurrección de Jerusalén y las basílicas de Tiro y de Antioquía.

${ }^{20}$ Las Constituciones Apostólicas es el nombre de una obra cristiana del siglo IV que se presentó como redactada por los apóstoles. Fue condenada por el Concilio Quinisexto por arriana, pero eso no invalida los datos que aporta para entender los usos de la Iglesia primitiva.

${ }^{21}$ Un dato curioso es que en el calendario mozárabe figura el 25 de marzo como "Equinoctium verni; mundi dies primus" (Agustí, Voltes 1952, p. 35). Aproximadamente el 25 de marzo
} 
el punto de vista astronómico. Sin embargo esta orientación precisa es más la excepción que la regla.

\section{CRITERIOS DE ORIENTACIÓN DE LOS TEMPLOS ROMÁNICOS}

Ya se ha comentado que la orientación solar es de origen muy antiguo. Sin embargo el precedente inmediato de los templos cristianos debe buscarse en la cultura grecolatina que enlaza con el mundo románico a través de la arquitectura prerrománica en sus diversas manifestaciones.

Vitrubio en su libro IV cap. 5 da algunas indicaciones sobre la orientación de los templos que indican que para los constructores romanos no era una preocupación estricta, como luego lo será en los templos cristianos. Entiende que, en general, se deben orientar al este. Si hay algún obstáculo importante se cambia la orientación para que desde el templo se pueda contemplar la mayor parte de la ciudad. Si se construye al lado del río se orientará hacia las márgenes y lo mismo si se construye cerca de una vía pública importante. Como se ve, son criterios arquitectónicos y no simbólicos, al contrario de los que se emplearán en los templos cristianos.

En una orientación solar es posible calcular el día en el que la posición del orto o del ocaso del sol coincide exactamente con la alineación de una iglesia, considerando los efectos de los movimientos de la Tierra y la altura del horizonte por medio de cálculos astronómicos. Lo que suscita dudas es el significado de dicho día para sus constructores. Los datos básicos necesarios son la advocación del edificio, la fecha aproximada de su construcción, la orientación corregida con la declinación magnética, la pendiente del horizonte en especial si está fijada por un obstáculo natural como un monte o una cresta montañosa y la latitud del lugar. Estos datos han sido recopilados por los propios autores en una base de datos que es la fuente básica para este estudio.

Son posibles cinco criterios de orientación:

- Criterio topográfico. Existe la posibilidad sugerida por algunos investigadores de que la orientación fuera determinada por criterios de implantación en el terreno ${ }^{22}$, o que se pretendiera adaptar la orientación de la iglesia a una trama urbana consolidada, como se puede observar en diversos ejemplos y singularmente en ciudades de antigua tradición romana como Astorga o Lugo. Son criterios próximos a las teorías de Vitrubio, que son dudosos en el caso románico. En todo caso se revisará críticamente esta posibilidad.

era la fecha del equinoccio cuando Julio César estableció el calendario juliano (46 a.C.) y parece que la tradición se conservaba, pese a su evidente discrepancia astronómica y aún litúrgica.

${ }^{22}$ Sassin 2016. 
- Criterio geomagnético. Algunos investigadores, en especial daneses y suecos señalan la posibilidad de que las iglesias hubieran sido orientadas por medio de la brújula ${ }^{23}$. Pese a considerarse poco probable en el entorno hispánico, entendemos que debe ser analizado.

- Criterio simbólico. Podemos suponer que la iglesia se orientó en la fecha que corresponde a la fiesta del santo de su advocación. Es una hipótesis que se atribuye a Nissen, aunque tal atribución es discutible. Hay muchas discrepancias en la validez de dicha hipótesis en distintos entornos geográficos, pues autores como Cave y Hinton se oponen ${ }^{24}$, mientras que otros como Ali y Cunich $^{25}$ consideran que las correspondencias que han encontrado son lo suficientemente representativas. Por ello se considera necesario comprobar su posible validez en el campo de estudio elegido. Para ello se situará la orientación del edificio y el día del año y se comparará con la curva de ortos para intentar valorar las posibles coincidencias.

- Criterio litúrgico. La iglesia se orientó durante el período litúrgico de la Pascua, que al ser una fiesta variable podría justificar las diferencias de orientación. Las fechas posibles para la Pascua están entre el 22 de marzo y el 25 de abril. Entenderemos que este criterio podría ser válido si se apreciase una frecuencia significativa en este período.

- Criterio constructivo. La iglesia se orientó en el día de su replanteo, que fijaron los constructores por razones puramente constructivas. Este día habría sido elegido por la lógica constructiva de iniciar los trabajos en una fecha adecuada y en un periodo sin lluvia, sin preocuparse del significado que pudiera tener ese día. Un día de replanteo que reúna estas características puede producirse en cualquier fecha del año y por tanto pueden existir orientaciones que cubren cualquier punto de las posibles trayectorias solares.

\section{TOMA DE DATOS DE LA ORIENTACIÓN}

Suponiendo que el replanteo de las iglesias cristianas se hizo en la dirección del orto solar, es necesario tratar de determinar cómo. Es un problema ya antiguo y conocido en otras civilizaciones como la egipcia. Lull menciona que para el inicio de la obra de un templo se celebraba una ceremonia denominada "Estiramiento de la Cuerda" en la que la diosa Seshat y el dios Thoth o el faraón dirigían la situación del edificio marcada con cuerdas. Esta

\footnotetext{
${ }^{23}$ Abrahamsen 1992; Persson 2004.

${ }^{24}$ Hinton 2006.

${ }^{25}$ Ali, Cunich 2001, pp. 155-156.
} 
ceremonia que está referenciada desde el reinado de Dewen, el cuarto faraón de la dinastía I. Hay diversas teorías sobre el sistema utilizado para definir la orientación como los métodos propuestos por Maragioglio, Neugebauer, Isler o Edwards ${ }^{26}$. La mayor parte de estos métodos son complejos, pero posibles en una civilización como la egipcia que disponía de agrimensores expertos. En el contexto medieval son sumamente improbables.

Hay un antecedente interesante en Vitrubio (libro 1, cap. 6) que describe un sistema muy preciso para fijar una orientación norte-sur, pero su aparente sencillez no debe inducir a engaño. Es sabido que los pocos textos que se conservaron de Vitrubio carecen de los dibujos que sí debieron tener los originales y es difícil reproducir el sistema propuesto con la simple descripción contenida en el libro. Como en muchos otros aspectos el texto vitrubiano no es fácil de entender sin unos conocimientos geométricos previos y sólidos que es dudoso que tuvieran los constructores medievales.

Es conocido que los romanos utilizaban un instrumento sencillo (groma) que permitía hacer enfilaciones precisas en dos direcciones perpendiculares, por lo que tras fijar la orientación podían conseguir alineaciones con un error mínimo. Pero pese a su sencillez no se conoce ningún testimonio medieval de su uso, ni aparece en ninguna representación. Es probable que no se haya utilizado en ningún caso.

Descartando estos precedentes tanto por exigir una dirección de obra cualificada, como por la falta de cualquier prueba documental, debemos concluir que el replanteo se realizó sin duda con los únicos instrumentos disponibles que fueron simples estacas o barras de hierro clavadas en el suelo y cuerdas para fijar la posición de los distintos elementos. De hecho muchos de los replanteos que se pueden observar contienen errores importantes de paralelismo o perpendicularidad en el trazado.

Para marcar una orientación al orto solar basta con dos barras clavadas en el suelo para enfilar la salida del sol y a partir de las cuales se pueden trazar los hitos y cuerdas del replanteo. Hubiera bastado una única barra vertical y la sombra hubiera marcado la dirección, pero la enfilación con estacas es mucho más precisa y desde luego era común en la construcción romana y en las anteriores. La barra B desde la que se toma la referencia puede disponer de un agujero o una horquilla que permita una enfilación más precisa. Son instrumentos elementales al alcance de cualquier herrero. Incluso en alguna pintura medieval puede intuirse el procedimiento usado. De hecho en el álbum de Villard de Honnecourt aparecen algunos dibujos que sugieren el uso de cuerdas y estacas para medir distancias o pendientes, si bien no se muestra la toma de orientación.

\footnotetext{
${ }^{26}$ Lull 2006, pp. 290-302.
} 

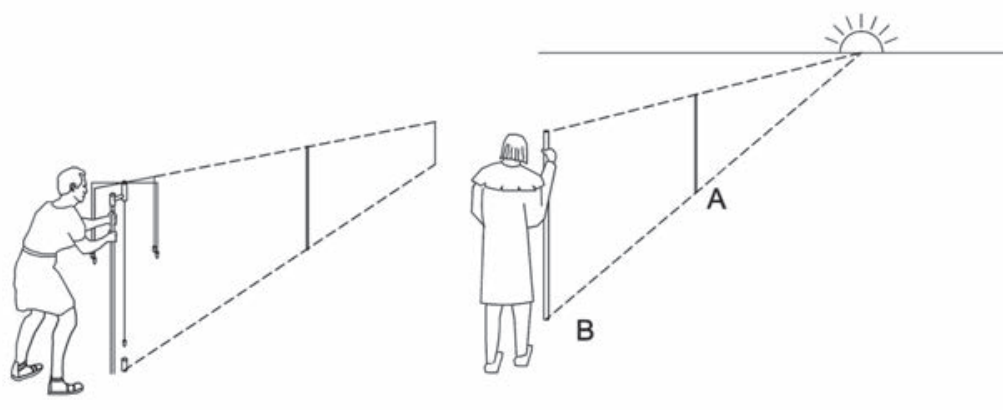

Fig. 2. Enfilación con groma y con estacas para definir la orientación del edificio.

Parece fuera de toda duda que las orientaciones de las iglesias medievales y específicamente de las románicas están orientadas en la dirección marcada por el sol, sea el orto, sea el ocaso y no en la dirección del este. Si la intención de los constructores hubiera sido orientarlas hacia el este geográfico, únicamente hubiera sido necesario determinar la posición del sol a mediodía y trazar una línea perpendicular a ella. Un simple palo clavado en el suelo cuando su sombra es más corta, es decir a mediodía, marca la dirección norte sur. Ni el más torpe de los constructores podría haberse equivocado en más de unos pocos grados y sin embargo hemos encontrado desviaciones de hasta $30^{\circ}$ del este geográfico tanto al norte como al sur. Solo es posible una explicación y es que la orientación haya sido deliberada y hacia el punto de salida o de puesta de sol. Y por las connotaciones simbólicas señaladas cabe suponer que en la mayor parte de los casos, salvo en los que es físicamente imposible, haya sido el orto solar.

En el momento actual la medición de la orientación tiene que hacerse con brújula, a ser posible, de precisión. No es viable el uso de dispositivos GPS puesto que no funcionarían en el interior de la iglesia y es relativamente frecuente que la orientación del ábside no coincida con la del eje del edificio. El replanteo siempre se hacía empezando por el ábside que es el primer elemento que se construía tanto por razones simbólicas como prácticas: a partir de su construcción ya se podía celebrar las ceremonias religiosas. En cambio la nave se construía después y a veces los obstáculos naturales y básicamente la pendiente del terreno aconsejaba girar su eje para acomodarla mejor al suelo. Por esa razón lo que define la orientación de la iglesia es el ábside.

En ocasiones hemos podido leer opiniones de algunos historiadores en el sentido de dar un valor simbólico a este cambio de eje. Se basan en suponer que reproduce en planta la forma de cruz con la cabeza de Cristo inclinada hacia la izquierda, como es común en la iconografía. Así se puede observar en 
la iglesia santa María de La Coruña que presenta una importante desviación entre ambos ejes de $6^{\circ} 30$ ' a la izquierda ${ }^{27}$. Sin embargo parecida desviación hacia la derecha se observa en otras iglesias y muy singularmente en S. Miguel de Almazán en Soria $\left(6^{\circ} 40^{\prime}\right)$. Es curioso que en ambos casos aparezca un fuerte desnivel del terreno que se evita con el giro del eje de la nave. Las desviaciones del ábside con respecto a la nave son bastante frecuentes tanto a la izquierda como a la derecha. Por ello pensamos que la única razón del giro de eje es la ligada a las condiciones de replanteo, sin razones simbólicas. En esto nuestra apreciación coincide con lo indicado por Hinton, que ha señalado la misma discrepancia en iglesias inglesas, llegando a las mismas conclusiones ${ }^{28}$.
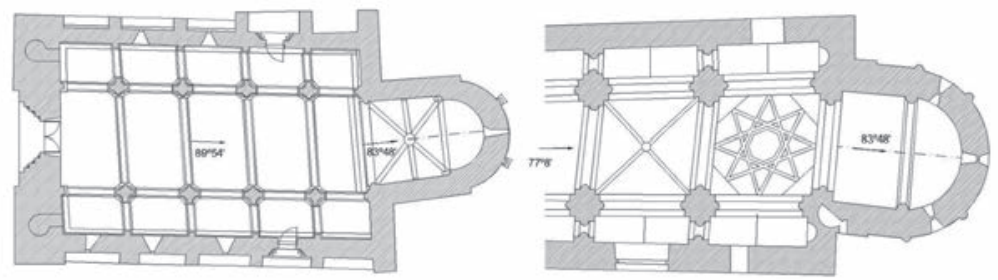

Fig. 3. Santa María del Campo (A Coruña) y San Miguel de Almazán (Soria)

Así pues la orientación debe tomarse en el ábside y el único instrumento eficaz es la brújula. Es un instrumento poco exacto en el que difícilmente se puede garantizar una precisión superior a $\pm 0,5^{\circ}$. Además hemos de considerar que la brújula mide la posición del norte magnético que forma con el norte geográfico un ángulo llamado declinación magnética: se considera positivo si el norte magnético está a la derecha del geográfico y negativo en el caso contrario. El resultado es que el ángulo real con el norte geográfico será el ángulo medido (referido al norte magnético) más la declinación magnética con su signo. Es un aspecto de la mayor importancia y con gran influencia en los resultados, que no siempre se ha tenido en cuenta.

La declinación magnética varía con las coordenadas geográficas (longitud y latitud) del lugar y la fecha de medición. El cálculo de esta declinación se ha realizado con el programa Geomag ${ }^{29}$ en las medidas tomadas antes de 2011 o para datos de iglesias fuera de España. A partir de 2011 para

\footnotetext{
${ }^{27}$ Soraluce 1989.

${ }^{28}$ Hinton 2006, p. 206.

${ }^{29}$ GeoMag (Geographic Magnetic Calculator) es un programa de uso libre desarrollado por Garry Petrie de Nestucca Drive, Portland, Oregon de gran utilidad e interés.
} 
las iglesias españolas se utiliza el calculador del Instituto Geográfico Nacional por estar más adaptado al territorio nacional. En ambos casos la precisión es muy superior a lo necesario.

Otro factor a tener muy en cuenta son las anomalías magnéticas, que pueden alterar gravemente las mediciones de la brújula. En grandes catedrales o abadías es frecuente la presencia de rejas de hierro de las que debemos alejarnos para una medición correcta. En ocasiones los refuerzos de acero de las restauraciones impiden medidas fiables como sucede en la cripta de Sta. Eulalia de Mérida. También existen lugares con anomalías magnéticas naturales como hemos podido comprobar en Sto. Tomé O Vello de Maside (Ourense). En todos los casos es necesario estar seguros de tomar medidas de orientación en condiciones adecuadas y en todos los casos dudosos se han contrastado los datos medidos con fotografías aéreas.

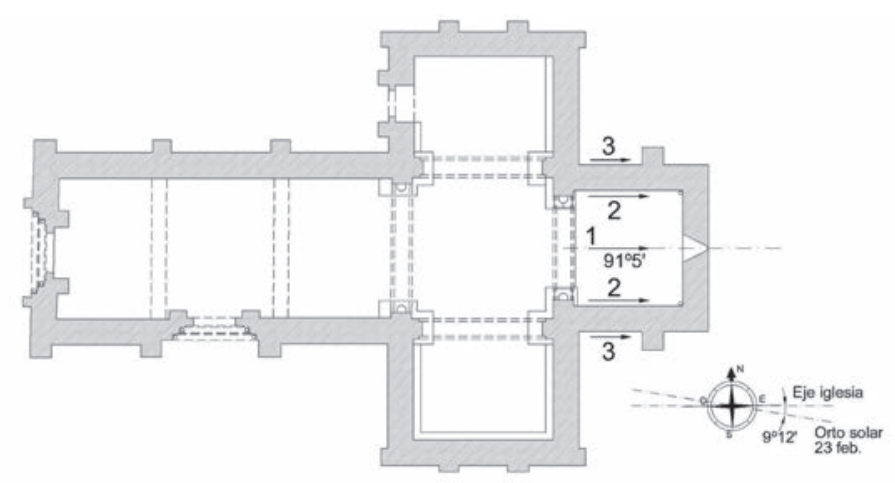

Fig. 4. Toma de datos de la orientación

Para la realización de este estudio se han tomado las orientaciones de eje del ábside y en su caso de la nave de la iglesia en todos los casos en los que han sido accesibles. Cuando no ha sido posible se han tomado las orientaciones desde el exterior en varios puntos significativos que se indican en la figura 4 que corresponde a Sta. Marta de Tera (Zamora). Se ha utilizado una brújula prismática con una escala en milésimas que permite un mejor ajuste y una precisión mayor. La escala en milésimas divide la circunferencia en 64 partes con 10 subdivisiones cada una, lo que supone una precisión de $360^{\circ} / 640=0,565^{\circ}$. En algunos casos las irregularidades del edificio y la falta de referencias fijas aconseja estimar en los cálculos un posible error de $\pm 1^{\circ}$ con respecto al valor medido. Para la medida de las pendientes del horizonte, imprescindibles para fijar la posición real del orto solar, se ha utilizado un medidor laser de la marca Leica, modelo DISTO ${ }^{\mathrm{TM}}$ D8 con clinómetro digital con una precisión de $0,05^{\circ}$. 


\section{FACTORES QUE INTERVIENEN EN EL CÁLCULO DE LA ORIENTACIÓN}

Para poder determinar el punto exacto de salida o puesta de sol es necesario hacer un cálculo astronómico que tiene bastante complicación ${ }^{30}$. Para ello los autores han desarrollado un programa de ordenador, ORIENT 2.0, que permite determinar con precisión los días del año en los que la orientación de una iglesia coincide con el orto o el ocaso, admitiendo el error señalado de $\pm 1,0^{\circ}$ en los datos medidos.

La trayectoria aparente del sol es una elipse de muy poca excentricidad que puede aproximarse sin apenas error por una circunferencia que está inclinada un ángulo igual a la latitud del lugar medido desde la vertical. Durante los equinoccios el sol sale exactamente a 90 grados desde el norte, lo que corresponde al punto vernal $\Upsilon$ (aries). A lo largo del año varía por el cambio en el movimiento aparente del sol. Desde el equinoccio de primavera hasta el solsticio de verano, el orto solar se aproxima al norte por lo que la medida de su orientación es un ángulo inferior a $90^{\circ}$. En las latitudes en las que se encuentra el románico español puede llegar a unos $55^{\circ}$. Pasado el solsticio de verano del ángulo empieza aumentar. En el equinoccio de otoño vuelve al medir $90^{\circ}$ y en el solsticio de invierno puede llegar a unos $125^{\circ}$. Precisamente estos son los rangos de variación de las orientaciones de la mayoría de las iglesias medievales.

Para validar nuestro programa de cálculo es importante definir los parámetros que intervienen en el problema y su influencia. Los principales son sin duda los que definen la trayectoria solar, pero hay otros que también influyen y cuya influencia no se puede ignorar. De ellos son esenciales la latitud del lugar que define la inclinación de la trayectoria y la inclinación del plano de la eclíptica que define la desviación anual de la trayectoria aparente. Este ángulo es fijo, al menos para períodos cortos y en el momento actual es de $23^{\circ} 26^{\prime} 14$ '. Los siglos del románico están lo suficientemente próximos para no necesitar ajustes. Además es necesario hacer una pequeña corrección para tener en consideración la forma elíptica real de la trayectoria solar, pero su influencia es pequeña. No obstante el programa hace esta corrección.

Si el horizonte fuera plano los cálculos realizados podrían permitir la determinación precisa de las posiciones del orto y ocaso en cualquier día del año. Sin embargo la existencia de cualquier elevación en el horizonte hace que la posición de la salida del sol corresponda a un momento en el que el sol ha recorrido ya parte de su trayectoria aparente. Esto hace que una iglesia orientada hacia el orto solar en un horizonte con pendiente esté orientada hacia un

${ }^{30}$ Duffett-Smith 1988, pp. 52-61, 93-95. 
punto C que está situado unos pocos grados hacia el sur desde el punto de salida del sol en un horizonte plano D. Por tanto si se desea calcular exactamente el día en el que la iglesia fue orientada es necesario corregir su orientación para tener en cuenta este efecto. Esto supone muchas complicaciones. Por una parte los cálculos son relativamente complejos ${ }^{31}$ y por otra los obstáculos en el horizonte pueden ser razonablemente inamovibles como montañas, pero en otros el obstáculo que percibimos, como construcciones, taludes, árboles, etc. pueden haber aparecido después de la construcción y por ello no afectaron a quienes la ejecutaron. A veces esto supone una dificultad muy grande y a veces una incertidumbre en los resultados.

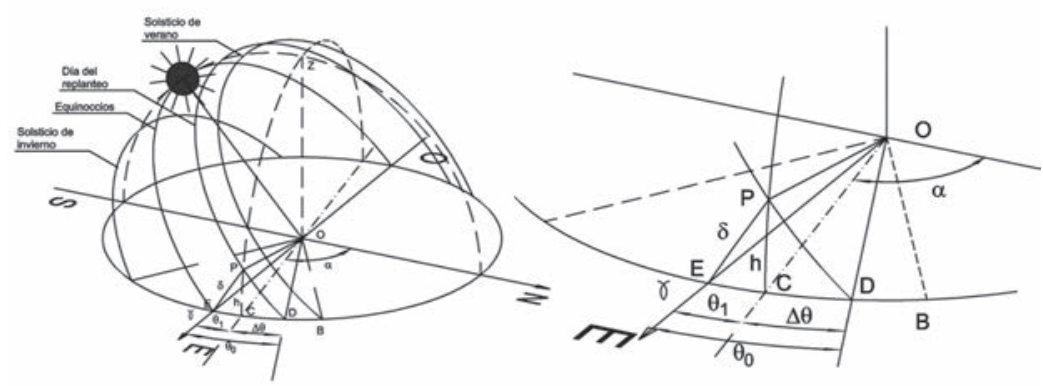

Fig. 5. Efecto de la elevación del horizonte en la orientación.

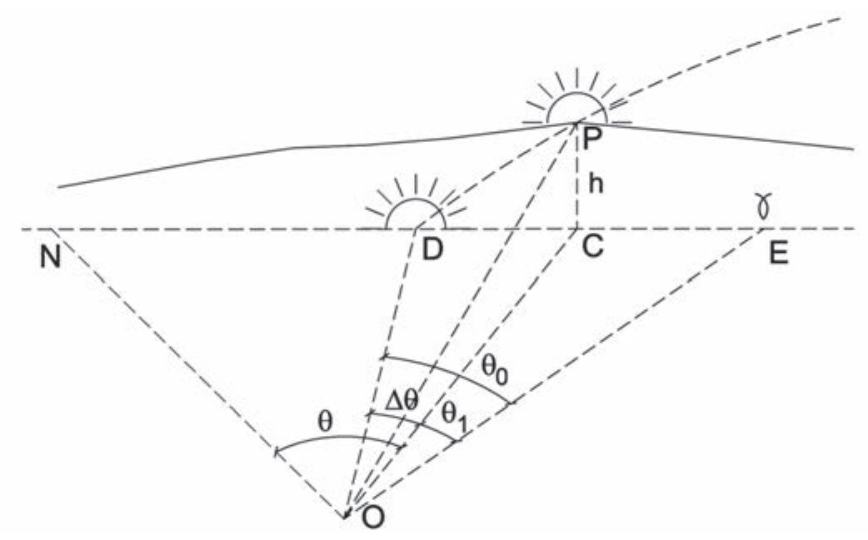

Fig. 6. Cálculo de la variación del orto con la pendiente del horizonte.

${ }^{31}$ Rodríguez, Blanco, Muiños 2012. 
La variación viene dada por la ascensión recta $\theta$ y los datos conocidos son la latitud $\varphi$ y la altura h que sería el ángulo con la horizontal de la salida del sol tras el obstáculo ${ }^{32}$. Como la trayectoria del sol salvo en el equinoccio es un círculo menor, es necesario utilizar una fórmula aproximada, pero lo suficientemente precisa para nuestro objeto. Las fórmulas para el cálculo son:

Ángulo del orto desde el este $\theta_{1}$

$$
\theta_{1}=90-\theta
$$

Declinación del paralelo celeste

$$
\operatorname{sen} \delta=\operatorname{sen} \varphi \cdot \operatorname{sen} \mathrm{h}-\cos \varphi \cdot \cos \mathrm{h} \cdot \cos \theta
$$

$$
\begin{aligned}
& \mathrm{A}_{0}=\arccos \left(-\frac{\operatorname{sen} \delta}{\cos \varphi}\right) ; \theta_{0}=90-\mathrm{A}_{0} \\
& \Delta \theta=\theta_{0}-\theta_{1}
\end{aligned}
$$

La latitud del románico español está entre los $41^{\circ}$ y los $44^{\circ}$. Esto hace de la variación de la ascensión recta sea algo menor que la declinación del sol en el orto. La influencia de este factor es muy variable. En muchas de las iglesias el horizonte está razonablemente despejado, pero las hay situadas en fuertes pendientes como en S. Estevo de Ribas de Miño (Lugo), S. Pantaleón de Losa (Burgos) o S. Joan de Boí (Lleida) en las que la influencia de la pendiente es importante, al estar cerrado el horizonte en la dirección del edificio por una fuerte elevación del terreno.

La fecha de construcción también influye pero no es necesario determinarla con precisión sino de forma aproximada. La razón de este hecho es que las iglesias románicas se construyeron en una época regida por el calendario juliano y su uso implicaba un retraso de tres días cada cuatrocientos años. En el siglo XII por ejemplo el retraso desde el concilio de Nicea (siglo IV) donde se establecieron las principales fiestas religiosas del cristianismo, era de seis días. Así una festividad fijada para el 12 de marzo en realidad astronómicamente corresponde a la orientación del 6 de marzo. Para evitar este problema el programa usado emplea el calendario juliano, lo que por otra parte es normal en cálculos astronómicos. Con todo y puesto que el período del románico hispánico abarca unos dos siglos y el error es de un día cada 133 años, un fallo incluso notorio en la fecha de un edificio es menos importante que los posible errores de medición.

La latitud, inclinación de la eclíptica y pendiente del horizonte son los tres aspectos fundamentales a tener en cuenta, a los que hay que añadir la

\footnotetext{
${ }^{32}$ La ascensión recta es el ángulo sobre el plano horizontal entre el punto vernal y el punto calculado.
} 
necesidad de utilizar fechas julianas. Existen otros efectos que pueden alterar la posición del orto solar, pero tienen menos importancia. Se suele citar el movimiento de precesión de los equinoccios que es esencial en los cálculos realizados en las orientaciones de diversos monumentos egipcios. Sin embargo para nuestro caso su importancia es mucho menor. El movimiento de precesión afecta a la posición con respecto a las estrellas, que en los monumentos egipcios se hacía con frecuencia, pero afecta muy poco a la trayectoria solar. Además el período de este movimiento es de 25.776 años por lo que en un período de tres a cuatro mil años tiene influencia, pero para las iglesias románicas el tiempo transcurrido no llega a los mil años. Pese a ello el algoritmo utilizado lo tiene en cuenta como factor de corrección. También la Tierra tiene otro movimiento llamado nutación, pero su influencia es casi nula, mucho menor que los posibles errores de los instrumentos de medida.

\section{ANÁLISIS DE LOS CRITERIOS DE ORIENTACIÓN EN LOS TEMPLOS ROMÁNICOS EN HISPANIA}

Con estas premisas el programa ORIENT permite calcular el día en el que la posición del orto o del ocaso del sol coincide exactamente con la alineación de una iglesia, considerando los efectos de los movimientos de la Tierra y la altura del horizonte. La precisión obtenida es la de la propia medida de la orientación que debe realizarse con especial cuidado y atención a las posibles anomalías magnéticas para conseguir resultados fiables. En consecuencia podemos afirmar que es posible calcular con precisión el día en el que fue replanteado cada uno de los templos estudiados. Puesto que hemos estimado la precisión de la medida en $\pm 1^{\circ}$, el margen temporal es diferente: el posible error de medición hace que en los equinoccios pueda haber una variación de unos tres días en la fijación de la fecha de replanteo, mientras que en los solsticios el margen puede llegar a unas dos semanas. La única duda es el significado de dicho día para los constructores que lo realizaron.

Como ya se ha comentado son posibles cinco criterios de orientación, topográfico por su implantación en el terreno, geomagnético por el uso de la brújula, simbólico por la fiesta del santo titular, litúrgico por la Pascua o funcional por el día elegido para el replanteo con consideraciones constructivas. Se ha rechazado la posible fecha del 1 de mayo, tanto por la falta de tradición en Hispania, como por las pocas coincidencias observadas. Para poder analizar la fiabilidad de estos criterios los autores han medido las orientaciones de un total de 699 iglesias románicas que abarcan la parte norte de España y Portugal, en el área de difusión del románico. En estas medidas se ha considerado el efecto de la declinación magnética y se han corregido 
considerando la pendiente del horizonte medida desde la posición de la iglesia. Con estos datos se ha realizado un estudio crítico de las cinco hipótesis que se plantean.

El criterio topográfico es fácilmente rebatible por la simple observación de muchas de las iglesias. Parece evidente que en el período románico la exigencia de la orientación al orto solar sustituye a cualquier otra consideración funcional en la mayoría de los casos. Podemos citar ejemplos extremos como las iglesias de los monasterios de Caaveiro (A Coruña) o S. Frutos de Duratón (Segovia) que la orientación este hace que el ábside deba ser colocado sobre un zócalo de gran altura para salvar el desnivel del terreno. En otros casos como Carboeiro (Pontevedra) o las iglesias aragonesas de Sos del Rey Católico, Muro de Roda, Loarre, Murillo de Gállego o Roda de Isábena se aprovecha el desnivel del ábside para construir una cripta. En S. Pedro das Aguias (Portugal) el espacio es tan estrecho que apenas queda sitio para entrar en la iglesia por la portada oeste, que además es la más monumental. Incluso en ocasiones como en Isil (Lleida) o Pitões das Junias (Portugal), el ábside penetra sobre un río al no disponer de terreno suficiente. En ambos casos son ríos de montaña, caudalosos y rápidos, lo que debió suponer enormes dificultades para resolver la cimentación. En todos los ejemplos citados el templo podía construirse en terreno suficiente de haber cambiado la orientación.

Sin duda hay casos en los que el edificio tiene una orientación que no corresponde a ningún punto del orto solar y que sin embargo es congruente con la trama urbana. Cuando se hable de las orientaciones atípicas se comentarán los casos de Astorga, Rivadavia o Portomarín y a ellos podríamos citar otros como la Magdalena de Zamora o Santiago de Puentelareina cuya situación puede estar determinada por la trama urbana aunque también puede corresponder a la orientación solar. Sin embargo estos casos y algunos otros son una clara minoría, por lo que entendemos que este criterio pudo ser usado ocasionalmente, pero en modo alguno es una pauta general.

Para analizar los criterios geomagnético, simbólico y litúrgico emplearemos la figura 7 en la que se representa la curva de ortos que corresponde al siglo XII, el más habitual de las construcciones románicas españolas. Sobre la curva se señala la posición de cada iglesia representando en abscisas la fecha juliana de la festividad del patrón y en ordenada la orientación corregida con la pendiente del terreno. Se señalan también las franjas en las que debieran situarse las iglesias de ser ciertos los criterios geomagnético y litúrgico. 


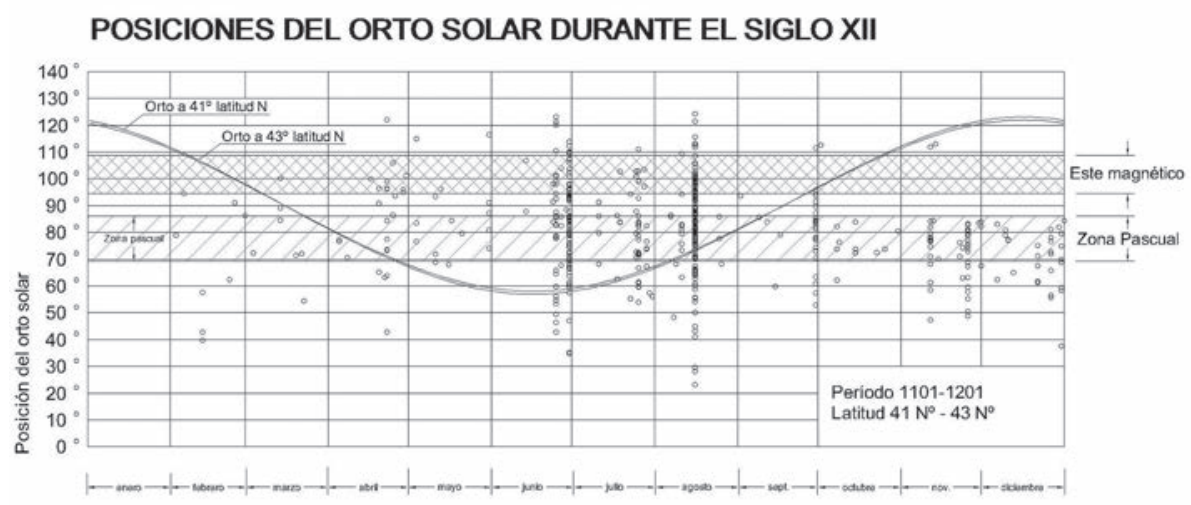

Fig. 7. Correlación entre la posición de la iglesia y la festividad de su patrón.

En primer lugar analizamos la posible validez del criterio geomagnético. Los investigadores nórdicos que han sugerido esta posibilidad se basan en una frecuencia anómala de orientaciones superiores a $90^{\circ}$ que se producen en invierno, que en esas latitudes no es una fecha lógica para iniciar obras y tampoco se corresponde con una proliferación de festividades de santos que pudieran indicar una orientación simbólica. Lo cierto es que durante los siglos del románico la declinación magnética hizo que el este magnético estuviera situado entre $100^{\circ}$ y $120^{\circ}$, en la zona nórdica. Son valores excesivos y congruentes con el posible uso de una brújula primitiva. En el entorno hispánico los resultados del programa SCHA.DIF.3K de la Universidad Complutense ${ }^{33}$ permiten determinar que para una posición intermedia que podemos fijar en Palencia, los límites de variación son de $108,79^{\circ}$ en el año 1000 y de $94,44^{\circ}$ en el año 1300 , menores que en latitudes nórdicas y que pueden tomarse como referencia puesto que las variaciones con la situación son reducidas. De haberse utilizado una brújula para determinar las orientaciones debería haber un número significativo de iglesias orientadas en esa franja.

Se observa en la figura 7 que sólo hay 113 iglesias orientadas entre dichos límites, es decir un 16,14\% del total, que es un porcentaje excesivamente bajo para considerar una correlación plausible. La mayoría de las iglesias están situadas fuera de esa franja y de hecho la tendencia es justamente la opuesta. Tampoco hay esa tendencia en iglesias de grandes monasterios o promovidas por la alta nobleza, en la que pudiera haberse introducido esta técnica, evidentemente novedosa. Entendemos por tanto que en el entorno

${ }^{33}$ Pavón-Carrasco, Osete, Torta, Gaya-Piqué 2009. 
hispánico esta hipótesis debe ser rechazada, al igual que otros investigadores lo han hecho en el entorno anglosajón.

Para analizar la validez del criterio simbólico se utiliza la misma carta solar anterior en la que se ha fijado la posición de cada iglesia por día del año el de la fiesta de su patrón y la dirección en la que está orientada. De haber sido replanteada en ese día concreto su posición en el gráfico debiera coincidir, siquiera aproximadamente con la curva de ortos.

Para poder situar correctamente las iglesias en el gráfico es necesario conocer la advocación concreta del templo, la fecha aproximada correspondiente al año de su construcción y el día en que se celebraba la fiesta es ese año de acuerdo con el calendario. Como se verá, esto tiene dificultades muy grandes en bastantes casos. En España hay la dificultad añadida de la existencia de dos calendarios sucesivos, uno específico, el mozárabe o toledano y otro posterior, el romano. Además existen muchas variedades de santorales derivados o relacionados con el mozárabe y es necesario considerar que algunas festividades de santos de gran importancia y muy usados en esta época como el Salvador, Santiago, S. Cristóbal, S. Julián, Sta. Cecilia o Sta. Columba varían sustancialmente con el santoral romano. Sería pues necesario saber si la onomástica se fijó de acuerdo con uno u otro calendario.

Se ha tomado como referencia la obra de Agustí y Voltes ${ }^{34}$ en la que se definen las festividades de los distintos calendarios medievales españoles. También se han comprobado algunos datos con el santoral de Recemundo, obispo de Granada, escrito en 961 y recopilado por Francisco Simonet ${ }^{35}$. En algún caso las diferencias son notables como pasa con la festividad de Santiago, que según el calendario mozárabe se celebra el 30 de diciembre en tanto que según el calendario romano se celebra el 25 de julio ${ }^{36}$. El rito romano fue introducido en Castilla por Alfonso VI en 1077, tras un "Juicio de Dios" como mínimo tramposo ${ }^{37}$ y con gran oposición. Podemos estimar que a partir de la conquista de Toledo en 1085 ya se consolida. A los efectos de este trabajo consideramos que las iglesias anteriores a esta fecha se orientaron por el calendario mozárabe, en tanto que las posteriores lo hicieron ya por el romano, si bien siempre hay dudas.

\footnotetext{
${ }^{34}$ Agustí, Voltes 1952.

${ }^{35}$ Simonet 1871.

${ }^{36}$ Según el santoral de Recemundo al menos una parte de los mozárabes también consideraban la fiesta de Santiago el 25 de julio.

${ }^{37}$ Estévez (ed.) 2003,p. 180. Según la Crónica Najerense se hizo una gran hoguera a la que se arrojaron dos misales uno con el rito romano y otro con el toledano (mozárabe). Como el misal toledano saltó de la hoguera, el rey enfadado lo devolvió de una patada diciendo "Quo volunt reges, vadunt leges"
} 
La simple observación de la figura 7 muestra con claridad que no hay correlación alguna entre las festividades de los santos y las orientaciones. Son notables algunas festividades especialmente numerosas como las de S. Juan Bautista (24 de junio), S. Pedro (29 de junio), Sta. María (15 de agosto) ${ }^{38}$ o S. Miguel (29 de septiembre), en la que se observa que se producen casi todas las orientaciones posibles. Se señalan específicamente estas festividades tanto por su frecuencia como porque coinciden en todos los calendarios medievales consultados.

Siempre se suscita la duda de si la advocación que hemos podido documentar (siempre la más antigua conocida) es o no correcta. Sin embargo en aquellos casos en los que no existe ninguna duda, como por ejemplo la catedral de Santiago, que obviamente siempre mantuvo esa advocación, su orientación con la corrección de pendiente corresponde al 15 de abril o al 15 de agosto, que no tienen relación alguna con festividades de Santiago. Lo mismo sucede en la mayoría de los casos en los que hay constancia cierta de la advocación, por lo que las posibles y raras coincidencias carecen de valor estadístico.

No es posible proporcionar la lista completa de las orientaciones medidas que se refieren a templos de todo tipo, catedrales, iglesias monásticas, iglesias parroquiales, ermitas, santuarios, etc. y situados en toda la zona estudiada. Sin embargo y a título de ejemplo se ha seleccionado una muestra representativa que corresponde a la ciudad de Zamora. Es una caso especial, puesto que se da una coincidencia mucho mayor que la habitual entre la posición del orto solar y el simbólico. De hecho un 42,1\% de las iglesias medidas tienen una desviación inferior a 11\% (en cursiva). Pero incluso en ese entorno hay desviaciones muy notorias como S. Leonardo, S. Esteban, S. Vicente, Sto. Tomé y Sta. Lucía, con festividades de invierno y orientaciones de verano.

Tabla 1

\begin{tabular}{lccccc} 
Iglesia & LugAR & FESTIVIDAD & $\begin{array}{r}\text { ORTO } \\
\text { REAL }\end{array}$ & $\begin{array}{r}\text { ORIENT. } \\
\text { SimB. }\end{array}$ & DESVIACIÓN \\
\hline Santiago de los Caballeros $^{39}$ & Zamora & $25-7$ & 99.18 & 64.92 & -34.26 \\
Espíritu Santo $_{\text {S. Pedro }}^{\text {Zamora }}$ & $10-5$ & 93.44 & 63.91 & -29.53 \\
S. Juan Bautista & Zamora & $29-6$ & 66.44 & 58.00 & -8.44 \\
& Zamora & $24-6$ & 65.88 & 58.10 & -7.78
\end{tabular}

\footnotetext{
${ }^{38}$ Esta fecha es la principal festividad de la Virgen. Hay iglesias dedicadas a otras festividades que se asignan a ellas.

${ }^{39}$ En esta iglesia es dudoso el calendario empleado por lo que aportan las dos posibilidades, ambas muy alejadas de la curva de ortos.
} 


$\begin{array}{lccccc}\text { S. Salvador (catedral) } & \text { Zamora } & 13-3 & 95.69 & 91.07 & -4.62 \\ \text { Sta. María } & \text { Zamora } & 15-8 & 75.94 & 73.62 & -2.32 \\ \text { Sta. María de Horta } & \text { Zamora } & 15-8 & 72.07 & 73.62 & 1.55 \\ \text { S. Isidoro } & \text { Zamora } & 4-4 & 76.57 & 79.62 & 3.05 \\ \text { Sta. Magdalena } & \text { Zamora } & 22-7 & 55.19 & 63.78 & 8.59 \\ \text { Santiago del Burgo } & \text { Zamora } & 25-7 & 54.07 & 64.92 & 10.85 \\ \text { Sto. Sepulcro } & \text { Zamora } & 25-3 & 72.07 & 84.33 & 12.26 \\ \text { S. Claudio de Olivares } & \text { Zamora } & 30-10 & 80.51 & 101.25 & 20.74 \\ \text { Santiago de los Caballeros* } * & \text { Zamora } & 30-12 & 99.18 & 120.84 & 21.66 \\ \text { S. Cipriano } & \text { Zamora } & 14-9 & 59.69 & 87.78 & 28.09 \\ \text { S. Frontis } & \text { Zamora } & 25-10 & 73.75 & 108.85 & 35.10 \\ \text { S. Leonardo } & \text { Zamora } & 6-11 & 70.33 & 113.68 & 43.35 \\ \text { S. Esteban } & \text { Zamora } & 26-12 & 76.57 & 121.48 & 44.91 \\ \text { S. Vicente } & \text { Zamora } & 22-1 & 65.25 & 114.31 & 49.06 \\ \text { Sto. Tomé } & \text { Zamora } & 21-12 & 67.57 & 121.99 & 54.42 \\ \text { Sta. Lucía } & \text { Zamora } & 12-12 & 66.94 & 122.17 & 55.23\end{array}$

El criterio que hemos llamado litúrgico, consiste en suponer que las iglesias se replantearon de forma preferente durante la Pascua. La fijación de las fechas de Pascua quedó zanjada en el Concilio de Nicea. Al contrario de la tradición judía que emplea un calendario lunisolar complejo, se dictaminó que la Pascua cristiana se celebraría el domingo de la primera luna llena de primavera es decir posterior al 21 de marzo, que en la fecha del concilio correspondió al equinoccio de primavera. El equinoccio "oficial” era el 21 de marzo, aunque la variación del calendario juliano hizo que él equinoccio se fuera trasladando a fechas anteriores en los siglos sucesivos. Así en el siglo XII, fecha de referencia en el románico de la Península Ibérica, el equinoccio se producía el 14 ó 15 de marzo y cuando se realizó la reforma gregoriana el día 11 de marzo. Por este motivo hubo que suprimir diez días para ajustar el calendario. Este hecho es de gran importancia en la interpretación de los cálculos puesto que la referencia de los constructores medievales era naturalmente la fecha juliana.

El día más temprano para la Pascua sería el 22 de marzo, y el más tardío el 25 de abril, pero en fechas julianas, que en ese siglo tenían ya seis días de retraso. Las orientaciones que corresponden al período pascual en fechas julianas en el siglo XII son:

$\begin{array}{ll}\text { Latitud } 41^{\circ} & \text { entre } 86^{\circ}(22 \text { de marzo }) \text { y } 70^{\circ}(25 \text { abril }) \\ \text { Latitud } 44^{\circ} & \text { entre } 86^{\circ}(22 \text { de marzo }) \text { y } 69^{\circ}(25 \text { abril })\end{array}$ 
Como se ve hay muy poca diferencia por latitud. Si dividimos el año en las fechas anteriores a la Pascua, las del período pascual y las posteriores a él, la estadística muestra un porcentaje significativo de iglesias $(43,59 \%)$ cuya orientación coincide con una fecha posible de Pascua. Con todo, nada nos puede asegurar esta hipótesis, puesto que la fecha varía de año en año y para hacer un estudio fiable necesitaríamos conocer el año exacto en el que se realizó el replanteo, cosa imposible.

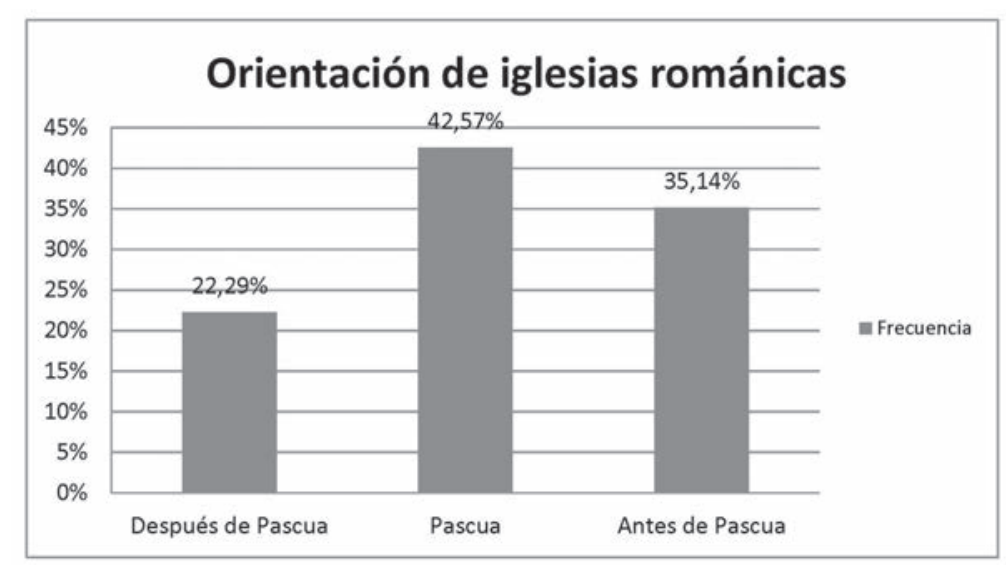

Fig. 8. Estadística de una posible orientación litúrgica de las iglesias románicas.

Al objeto de determinar algún posible criterio en la orientación de las iglesias, los únicos datos disponibles son los que derivan del propio objeto construido, es decir de las mediciones efectuadas sobre ellas. De las 699 obtenidas a día de hoy se puede realizar una estadística de sus orientaciones. Para ello hemos considerado los límites del orto solar en la zona de estudio que están entre $57^{\circ}$ y $123^{\circ}$ aproximadamente. Hemos dividido este ángulo en 12 sectores y analizado el número de iglesias cuyas orientaciones están en cada uno de los sectores y su frecuencia. Puesto que son muy pocas las iglesias orientadas en el solsticio de invierno consideramos un solo sector a partir de los $117^{\circ}$. Los resultados son los que siguen: 
Tabla 2

NÚMERO DE IGLESIAS ORIENTADAS SEGÚN EL ÁNGULO

\begin{tabular}{lcccccccccccc}
\hline \multirow{2}{*}{ ORIENTACIÓN } & & $57-$ & $63-$ & $69-$ & $75-$ & $81-$ & $87-$ & $93-$ & $99-$ & $105-$ & $111-$ & \\
EN $^{\circ}$ & $<57$ & 63 & 69 & 75 & 81 & 87 & 93 & 99 & 105 & 111 & 117 & $>117$ \\
\hline $\mathrm{N}^{\mathrm{o}}$ DE CASOS & 50 & 44 & 62 & 68 & 105 & 125 & 81 & 81 & 40 & 22 & 18 & 4 \\
$\%$ & 7,1 & 6,3 & 8,9 & 9,7 & 15,0 & 17,9 & 11,6 & 11,6 & 5,7 & 3,1 & 2,6 & 0,6
\end{tabular}

Para interpretar estos resultados hagamos una pequeña consideración. El día 1 de marzo corresponde a una orientación de unos $97^{\circ}$ en las latitudes estudiadas. Los ángulos menores de este valor corresponden a fechas posteriores, es decir el final del invierno, la primavera o el verano, fechas en las que un constructor sensato iniciaría las obras de una iglesia. Según nuestra estadística esto supone 473 iglesias, es decir el 83,13\% del total. Por el contrario las iglesias con orientaciones claramente de invierno suponen sólo el $16,87^{\circ}$.

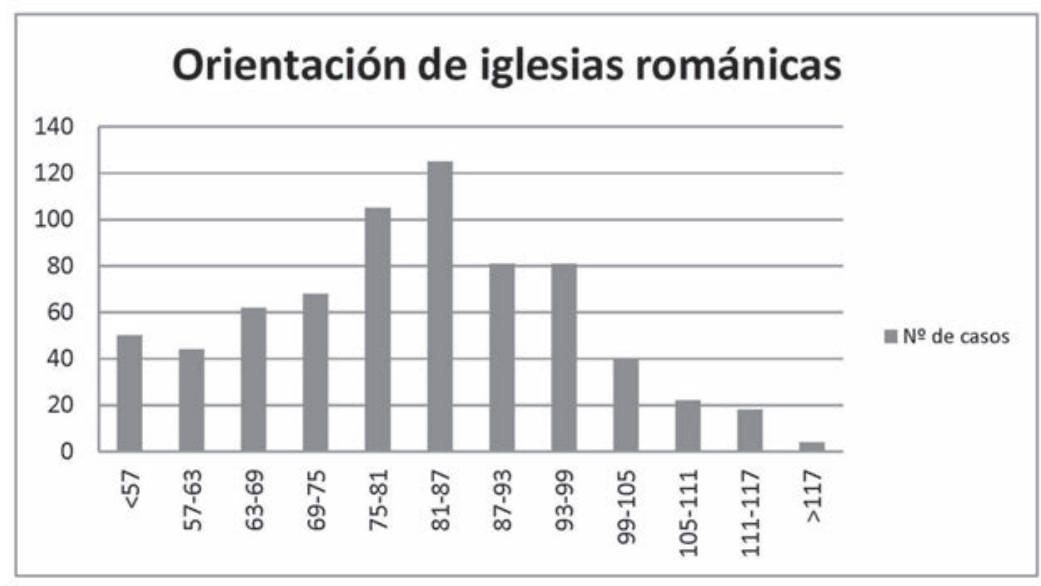

Fig. 9. Estadística de las orientaciones de las iglesias románicas

Aunque todo apunta a que el criterio más probable es el constructivo, algunos autores como Hinton hacen una seria crítica al mismo ${ }^{40}$. Su razonamiento se basa en que la lógica constructiva indica que no debe iniciarse una obra en invierno y de hecho existen contratos de obra que exigen iniciarla

\footnotetext{
${ }^{40}$ Hinton 2006, p. 217.
} 
después de una determinada fecha. El motivo es permitir que el mortero pueda fraguar en buenas condiciones. Sin embargo entendemos que no tiene que ser necesariamente así. Es perfectamente posible hacer el replanteo previamente a la excavación que puede ser muy complicada y lenta. Por otra parte es razonable que antes de iniciar la obra haya que disponer de una buena cantidad de roca que hay que extraer previamente de la cantera y cortar adecuadamente.

El replanteo no tiene por qué coincidir con el inicio de la obra. Es una fase previa y puede producirse con cierta antelación. Así podemos citar el caso mencionado por Nissen de la iglesia de la abadía de Limburg an der Haardt, dedicada a la Santa Cruz, con una orientación de $57^{\circ}$. Se colocó la primera piedra en presencia del emperador Conrado II el 12 de julio de 1030 y su orientación corresponde aproximadamente con esta fecha, que no coincide con la principal festividad de la Santa Cruz, el 3 de mayo, ni con ninguna otra (Exaltación de la Cruz 14 octubre). Se sabe que ese mismo día el emperador se trasladó a Espira (a unos $30 \mathrm{~km}$ ) para la consagración de su catedral dedicada a la Asunción y S. Esteban, con una orientación de $94^{\circ}$ y que tampoco coincide con ninguna de estas advocaciones, ya que corresponde a una fecha de principios de marzo o finales de septiembre. En este caso se menciona expresamente que las obras ya estaban iniciadas, por lo que el replanteo fue sin duda anterior.

Es war am 12 Juli des Jahres 1030, als Kaiser Conrad II bei Sonnenaufgang den ersten Stein legte zu der Klosterkirche auf Limburg a. H.: hierauf begab er sich nach Speier, wo man bereits den Grund gegraben und alles zum Bau Erforderliche vorbereitet hatte, um noch an dem nämlichen Tage den Grundstein zu dem dortigen Kaiserdom zu legen ${ }^{41}$.

\section{ORIENTACIONES ATÍPICAS}

La mayoría de las iglesias estudiadas tienen orientaciones que están dentro de los límites de las posiciones del orto solar en algún día del año. Son posiciones astronómicamente posibles. Existen algunas excepciones que podemos englobar en cinco aspectos.

En primer lugar existen algunas iglesias románicas con orientaciones al noreste que tienen un origen muy antiguo y probablemente están construidas sobre iglesias anteriores prerrománicas, en la que esta orientación se da con mayor frecuencia, u otros edificios anteriores construidos con otros cri-

\footnotetext{
${ }^{41}$ Nissen 1906, p. 402.
} 
terios de orientación. Así podemos citar casos como el monasterio de Ripoll o S. Facundo de Silió en Cantabria. De la base de datos total formada por 699 iglesias románicas construidas en la Península Ibérica hay 33 (4,72\%) cuyas orientaciones son menores de $54^{\circ}$ y por tanto no corresponden con ninguna posición del orto solar, ni siquiera considerando un error razonable de replanteo.

En otros casos la iglesia se construyó sobre una mezquita, que en España están normalmente orientadas al sur, pero es ese caso se cambió el sentido de la iglesia para distinguirse. Es el caso de S. Sebastián de Toledo con una orientación de $343^{\circ}$, es decir prácticamente a norte. Una solución muy ingeniosa es la del Cristo de la Luz en Toledo en la que a una pequeña mezquita cuadrada y orientada al sur se adosó una iglesia cristiana en su lado este, respetando así la orientación canónica.

También hay iglesias que se construyeron dentro de una trama urbana consolidada y que por tanto se ajustan a ella. Podemos citar Santiago de Ribadavia en Ourense o la catedral de Astorga que se construyó encima de la románica y que mantiene su orientación. También el caso de S. Xan de Portomarín (Lugo) construida originalmente en una trama urbana muy estrecha a orillas del Miño, en la que casi no hubiera existido ninguna otra opción ${ }^{42}$.

En el caso singular de las dos iglesias de S. Juan de la Peña, la dirección este es imposible de observar, al estar encajados sus ábsides en la montaña por lo que sin duda ambas iglesias se orientaron con la dirección del ocaso. También se observa este tipo de orientación en alguna ermita rupestre, fuertemente condicionada por la cueva original.

Por último hay un caso absolutamente atípico que es S. Serni de Tavèrnoles en Lleida con una orientación claramente hacia el oeste de $284^{\circ}$. No se conoce ningún dato que explique esta extraña orientación, que es excepcional en la Península.

\section{CONCLUSIONES}

Las conclusiones de este estudio son claras. En primer lugar consideramos que la orientación solar a levante es el criterio utilizado de forma sistemática en las iglesias románicas en Hispania. Se han mencionado diversos ejemplos, que podrían ser fácilmente ampliados, de edificios cuya implantación está condicionada por la orientación y es contraria a cualquier criterio

\footnotetext{
${ }^{42}$ Nos referimos a la situación original de la iglesia que ha podido determinarse aprovechando el vaciado del pantano de Belesar, puesto que ahora la zona está anegada.
} 
arquitectónico. Muchos edificios están situados de tal forma que su uso y su construcción se han visto seriamente limitados y sólo se justifican por el deseo de una orientación precisa.

Los datos que se citan permiten rechazar también la posible orientación con brújula puesto que la posible variación de la declinación magnética no se corresponde con los datos medidos.

El criterio simbólico de orientación no es compatible con los resultados obtenidos. Esto no quiere decir que no haya podido utilizarse en casos puntuales: de hecho hemos encontrado una coincidencia notable entre las orientaciones y las advocaciones de varias iglesias situadas en el núcleo amurallado de Zamora, pero ese criterio falla incluso en las iglesias extramuros de la misma ciudad. También se observa en algunos edificios aislados, algunos tan notables como Santa Sofía de Constantinopla, pero no es regla general ni tampoco particular en ninguna de las zonas estudiadas. Creemos poder afirmar con rotundidad que en la Hispania medieval no es el criterio utilizado.

El criterio litúrgico podría ser aplicado a un porcentaje significativo de iglesias, pero entendemos que en primer lugar no es fiable al carecer de datos del año concreto del replanteo y por otra parte el margen de error es estadísticamente relevante. Es posible y se plantea en el terreno hipotético, pero no existen en el momento actual pruebas suficientes para validarlo. Por otra parte el número de iglesias cuyas orientaciones está claramente fuera de ese período pascual es suficientemente representativo para hacer dudar de su validez.

En opinión de los autores el criterio más probable es el puramente constructivo. La iglesia en la mayoría de los casos se orientó el día del replanteo, en el momento en el que se iniciaron las obras y sin ninguna razón especial. El único aspecto simbólico es que se orientó en la dirección del orto solar y no hacia el este geográfico, lo que se hubiera podido conseguir sin gran esfuerzo. Es notable que incluso en monasterios importantes la orientación no es precisa, pese a que sin duda contarían con monjes que habrían estudiado astronomía (era una de las disciplinas del quatrivium). Incluso en alguno de ellos hemos observado la existencia de relojes de sol medievales, que exigen un buen nivel de conocimiento. De hecho el estudio del fenómeno de la "luz equinoccial" de Santa Marta de Tera ${ }^{43}$ (Zamora) muestra que el fenómeno se produce en el equinoccio astronómico y no en el equinoccio oficial en su época de construcción. Existen pruebas claras de que no es un fenómeno casual $91,09^{\circ}$.

${ }^{43}$ Está dedicada a Sta. Marta de Astorga (23 febrero, 99,85 $)$. Su orientación real es de 
y por ello resulta evidente que alguien tenía los conocimientos astronómicos precisos para determinar con precisión dicho equinoccio ${ }^{44}$. Por el contrario los conocimientos constructivos necesarios para conseguirlo son bastante sencillos y al alcance de cualquier constructor experto, como se demuestra en el citado artículo.

Como se vio en el apartado 5 para fijar el norte sólo es necesario situar la sombra de un palo vertical a mediodía, la hora sexta, que en un monasterio estaba sobradamente regulada y que también era de uso común en la vida diaria. Con toda seguridad habrían podido conseguir orientaciones al este real con un buen nivel de precisión con errores inferiores a los pocos grados. Si no lo hicieron, es porque en ningún momento fue esa su intención.

\section{BIBLIOGRAFÍA CITADA}

Abrahamsen, Niels (1973), Magnetic secular variation in Denmark 1500-1970, "Journal of Geomagnetism and Geoelectricity" 25, pp. 105-111.

Abrahamsen, Niels (1992), Evidence for Church Orientation by Magnetic Compass in Twelfth-Century Denmark, "Archaeometry" 34/2 pp. 293-303.

Ali, Jason R.; Cunich, Peter (2016), The Orientation of Churches: Some New Evidence, "The Antiquaries Journal” 81, pp. 155-193, DOI: 10.1017/ S0003581500072188.

Agustí y Casanovas, Jacinto; Voltes Bou, Pedro (1952), Manual de cronología española y universal, Madrid, CSIC, Escuela de Estudios Medievales.

Corbo, Virgilio (1981), II Santo Sepolcro di Gerusalemme. Aspetti archeologici dalle origini al periodo crociato, Jerusalem, Studium Biblicum Franciscanum (Collectio maior; 29).

Duffett-Smith, Peter (1988), Practical Astronomy with your Calculator, Cambridge, Press Syndicate of the University of Cambridge.

Estévez Sola, Juan A. (ed.) (2003), Crónica Najerense, Madrid, Akal (Clásicos Latinos Medievales y Renacentistas; 12).

Hinton, Ian (2006), Church Alignment and Patronal Saint's Days, "The Antiquaries Journal" 86, pp. 206-226.

Hinton, Ian (2010), Aspects of the Alignment and Location of Medieval Rural Churches, Norwich, University of East Anglia (tesis doctoral).

\footnotetext{
${ }^{44}$ Pérez Valcárcel, Pérez Palmero 2014.
} 
Hoare, Peter G.; Sweet, Caroline S. (2000), The Orientation of Early Medieval Churches in England, "Journal of Historical Geography" 26/2, pp. 162-173.

Hoare, Peter G. (2015), Orientation of English Medieval Parish Churches, en Ruggles, Clive (ed.), Handbook of Archaeoastronomy and Ethnoastronomy, Nueva York, Springer Reference, pp. 1711-1718.

Krautheimer, Richard (1984), Arquitectura paleocristiana y bizantina, Madrid, Cátedra (Manuales Arte).

Lull, José (2006), La astronomía en el antiguo Egipto, Valencia, Publicaciones de la Universidad.

McCluskey, Stephen C. (2015), Orientation of Christian Churches, en Ruggles, Clive (ed.), Handbook of Archaeoastronomy and Ethnoastronomy, Nueva York, Springer Reference, pp. 1703-1710.

Laužikas, Rimvydas (2015), Church Orientations in Central and Eastern Europe, en Ruggles, Clive (ed.), Handbook of Archaeoastronomy and Ethnoastronomy, Nueva York, Springer Reference, pp. 1727-1732.

Nissen, Heinrich (1896), Das Templum: Antiquarische Untersunchungen, Berlín, Weidmannsche Buchhandlung.

Nissen, Heinrich (1906), Orientation, Studien zur Geschichte der Religion, Berlín, Weidmannsche Buchhandlung.

Pavón-Carrasco, Francisco J.; Osete, María Luisa; Torta, J. Miquel; GayaPiqué Luis R. (2009), A Regional Archaeomagnetic Model for Europe for the Last 3000 Years, SCHA.DIF.3K: Applications to Archaeomagnetic Dating, "Geochemistry, Geophysics, Geosystems" 10/3, Q03013, doi: 10.1029/2008GC002244.

Pérez Valcárcel, Juan (1998), La orientación de las iglesias románicas del Camino de Santiago, en Actas del Segundo Congreso Nacional de Historia de la Construcción: A Coruña, 22-24 de octubre de 1998, Madrid, Instituto Juan de Herrera - CEHOPU, CEDEX, pp. 391-396.

Pérez Valcárcel, Juan; Pérez Palmero, Victoria (2014), El fenómeno de la luz equinoccial en Santa Marta de Tera, "Brigecio: revista de estudios de Benavente y sus tierras" 23, pp. 67-78.

Persson, Kjell (2004), The Orientation of Vendel Church, "Journal of Nordic Archaeological Science" 14, pp. 139-141.

Rodríguez Arós, Ángel; Blanco, Francisco; Muiños, María José (2012), Trigonometría plana y esférica con aplicaciones a la navegación, Madrid, Paraninfo.

Sassin Allen, Anne (2016), Church Orientation in the Landscape: a Perspective from Medieval Wales, “Archaeological Journal” 173/1, pp. 154-187, DOI: 10.1080/00665983.2016.1110781. 
Simonet, Francisco J. (1871), Santoral Hispano-Mozárabe escrito en 961 por Rabi Ben Zaid, obispo de Iliberis, Madrid, Tipografía de Pascual Conesa.

Soraluce Blond, José Ramón (1989), La Real Colegiata de Santa María del Campo de La Coruña, A Coruña, Diputación Provincial.

Fecha de recepción del artículo: febrero 2017

Fecha de aceptación y versión final: noviembre 2017 